\title{
UNA RUCA DONDE QUEPAMOS TODOS Y TODAS
}

\author{
Pedro Cayuqueo ${ }^{1}$
}

Comenzaré con una confesión; nunca pensé que sería testigo del despertar del pueblo chileno. Primero nos liberamos los mapuche, luego avanzamos sobre Santiago y, finalmente, invitamos a los chilenos a ser parte de nuestras ancestrales y democráticas formas de gobierno. Aquel era para mí el escenario más realista, y no que Chile despertara y menos aun enarbolando, de Arica a Magallanes, tres banderas de profundo significado: nuestra rebelde Wenufoye, la ceremonial Wüñelfe - aquella de campo azul y estrella blanca de ocho puntas - y también la ancestral WIPHALA de los pueblos andinos, "el triunfo que ondula al viento" en lengua aymara.

Pero el milagro aconteció: Chile despertó y lo hizo, de manera doblemente sorpresiva para mí, identificando sus propios anhelos de cambio social y profundización democrática con aquella larga lucha de nuestros pueblos por reconocimiento y dignidad, por justicia y reparación. Este despertar chileno, fruto de la revuelta social del 18 de octubre de 2019, es, sin duda, el principal hito del periodo que aborda el presente Anuario sobre el conflicto en WALLMAPU, el lado occidental del país mapuche. Cómo este hito dialoga con nuestra lucha en sus causas más directas —-desigualdad social, crisis de la política representativa, desborde de la institucionalidad- y sobretodo en sus consecuencias más inmediatas —violación de derechos humanos, tal vez su cara más dramática- es una de las interrogantes que este Anuario busca dilucidar. Enhorabuena.

Todo esfuerzo tendiente a observar en profundidad lo que sucede en las regiones del sur del Biobío merece ser valorado y acompañado. Los y las investigadoras que aportaron sus análisis para este libro poseen una brillante trayectoria. En su mayoría llevan años, cuando no décadas, estudiando el conflicto desde sus diversas disciplinas y perspectivas académicas. Desde el

1 Investigador independiente pcayuqueo@mapuchetimes.cl 
derecho indígena a la sociología crítica; desde la historiografía decolonial a las actuales luchas de género; desde el análisis de las políticas públicas al tan necesario enfoque de derechos humanos. Todo señalado desde un genuino compromiso con las vías pacíficas de resolución de conflictos, posiblemente el gran déficit en toda esta (mala) historia.

Pero más que comentar cada uno de los trabajos que componen esta obra - tarea que es vuestra, queridos lectores y lectoras- permítanme que aporte también una mirada propia sobre este 2019 de estallidos sociales y esperanzas constituyentes.

Hasta antes de aquel octubre, parto reconociendo, dudaba seriamente que aquel letargo neoliberal chileno llegase algún día a su fin. Los mapuche en cambio, desde el día dos del retorno de la democracia, identificamos al modelo económico y al pacto social heredado de la dictadura como dos adversarios centrales de nuestra lucha. Quinquén y Truf-Truf, Ralco y Lumaco, cuatro emblemáticos conflictos con mega empresas constructoras, hidroeléctricas y forestales que tempranamente instalaron en Wallmapu la contradicción Pueblo Mapuche / modelo de desarrollo; Pueblo Mapuche / institucionalidad del Estado. Treinta años han pasado y seguimos luchando.

Sí, el despertar mapuche fue mucho antes que el chileno y los costos que hemos debido pagar han sido tan altos como dolorosos.

Mientras escribo estas letras, el Tribunal de Juicio Oral en lo Penal de Angol acaba de anunciar la reprogramación, para el 21 de enero de 2021, del inicio del juicio oral en contra del coronel de Carabineros en retiro Marco Aurelio Treuer, acusado del crimen - mediante un escopetazo en la cabeza- del adolescente mapuche Álex Lemun. Los hechos acontecieron en noviembre del año 2002 al interior del fundo Santa Alicia de Angol, en el marco de un violento desalojo policial. Hablamos de un crimen que ha permanecido impune por veinte años. ¡Dos largas décadas!

No muy lejos de aquel fundo, al interior del lof Temucuicui de Ercilla, Camilo Catrillanca sería acribillado por efectivos del GOPE en noviembre del año 2018. El juicio contra los responsables, también radicado en el Tribunal de Angol, debería reanudarse el próximo 27 de octubre tras ser postergado hace medio año por la crisis sanitaria global. Siete son los ex funcionarios de Carabineros acusados por el Ministerio Público, además de un abogado civil. Se les imputa homicidio consumado, homicidio frustrado, apremios ilegítimos, obstrucción a la investigación, falsificación de instrumento público, infidelidad en la custodia de documentos y prevaricación, entre otros delitos. Dos casos judiciales que son noticia mientras redacto estas líneas.

Pero los chilenos, tras el Estallido Social, también han pagado un alto costo por su rebeldía. Según un informe del Instituto Nacional de Derechos Humanos, desde octubre de 2019 se han reportado en Chile 490 casos de torturas y vulneración de derechos en manos de Carabineros. Entre ellos, 112 corresponden a casos de violencia sexual. El informe constata, además, 259 casos de heridas oculares, entre ellos Gustavo Gatica y Fabiola Campillay quienes perdieron dramáticamente la vista en ambos ojos.

Nada hace suponer que intervenir y reformar Carabineros sea una prioridad para la actual administración. Todo lo contrario. En días recientes un joven manifestante terminó gravemente herido, en el lecho del río Mapocho, tras ser lanzado allí por un efectivo policial desde el Puente Pío Nono. Salvó con vida de milagro. Desatada la polémica, el respaldo de La Moneda a los protocolos y la — cito textual- "necesaria y fundamental labor de Carabineros", 
fue absoluto. El joven apenas tenía 16 años, misma edad de Alex Lemun al recibir aquel disparo fatal en su cabeza.

"Peñi, los abusos de Carabineros se han agravado; ahora cargan por igual contra todos, seamos o no mapuche", me comentó tiempo atrás un destacado lonko de Malleco. Su observación, cargada de crudo realismo, no deja de ser cierta. Pero de la misma forma que se ha generalizado la violencia y brutalidad policial, también lo ha hecho la solidaridad entre nuestros pueblos. Quizás como nunca antes. De ello trata el momento constituyente que estamos viviendo en Chile. Ad portas de un plebiscito histórico, la oportunidad de zafar de la camisa de fuerza constitucional heredada de la dictadura puede que sí valga el sacrificio. He allí nuestra esperanza.

Reescribir juntos, chilenos y mapuche, una nueva Carta Fundamental asomó en 2019 como un desafío democrático de primer orden. Ello podría canalizar pacífica e institucionalmente no solo los anhelos de justicia social de las grandes mayorías de chilenos y chilenas, también las postergadas aspiraciones de justicia, territorio y libertad del conjunto de las primeras naciones que, mucho antes que los descendientes de europeos, hicieron de este bello rincón del continente su hogar.

Fuera del proceso constituyente, les soy honesto, no veo a corto y mediano plazo caminos de solución a un conflicto que cada día en WALLMAPU recrudece en intensidad y violencia. Coincido en este punto con el realista diagnóstico de varios de los autores y autoras de este libro. Ya leerán también ustedes sus respectivos análisis. Entre ellos, la militarización que persiste en los territorios, la ineptitud - a ratos criminal- de quienes nos gobiernan, el diálogo y la negociación que brillan por su ausencia, y la incapacidad del Estado y sus instituciones para reconocer derechos, reparar el daño causado y transferir poder y competencias a nuestros pueblos.

El proceso constituyente, en cambio, nos ofrece una inédita oportunidad de diálogo interétnico con la sociedad no indígena, algo clave si queremos avanzar en un entendimiento mutuo más allá del Estado y sus deficiencias.

En momentos en que chilenos y chilenas se cuestionan tantas cosas - los negativos efectos del modelo económico, la mercantilización de derechos sociales, la corrupción política y el abuso de poder- bueno sería invitarlos también a repensar su relación con los pueblos originarios, a deconstruirse de más de un siglo de negación y menosprecio de sus verdaderos ancestros. Ello implica participar, aunar voluntades de cambio, no restarse. La nueva Constitución, plurinacional e intercultural, será la casa grande que heredaremos a las nuevas generaciones. Que sea una ruca donde por fin quepamos todos y todas.

Viña del Mar, octubre de 2020 